\title{
Mímesis e enigma: sobre Infância em Berlim por volta de 1900
}

Patricia Lavelle*

Patricia Lavelle*

RESUMO: Os textos especulativos sobre a faculdade mimética constituem esboços preparatórios para o projeto de Infância em Berlim por volta de 1900, e em particular para o primeiro capítulo de sua primeira versão datilografada (1932-1933), intitulado Mummerehlen. A problemática das "semelhanças não sensíveis" atravessa o texto, que pode ser compreendido como uma tentativa de domínio de seu poder mágico de tornar presente, isto é, como um exercicio de colocar à distância as forças míticas da imagem. Pois, deixando entrever o horizonte teórico implicado nas semelhanças artisticamente produzidas, Benjamin explicita e deforma o quadro mimético da representação, explicitando o valor cognitivo da obra. A modernidade destas memórias de infância está justamente em tematizar essa tensão entre poesia e teoria sobre a qual se constitui sua estrutura enigmática.

PALAVRAS-CHAVE: Benjamin, mímesis, enigma

\footnotetext{
*Patricia Lavelle é doutora em Filosofia pela EHESS-Paris e mestre em História pela PUC-Rio. É organizadora do livro Walter Benjamin (Paris: L'Herne, Col. Cahier de l'Herne, 2013) e autora de Religion et Histoire. Sur le Concept d'Expérience chez Walter Benjamin (Paris: Cerf, Col. Passages, 2008). É atualmente pesquisadora associada ao Centre Georg Simmel (EHESS-Paris) e bolsista da CAPES vinculada ao Programa de Pós-Graduação em História da UFRJ. E-mail: patricia.g.lavelle@gmail.com
} 
ABSTRACT: The theoretical texts about the mimetic faculty were written as preparatory works for the project of Berlin's Childhood around 1900, and in particular for the first chapter of its first version (1932-1933) called Mummerehlen. The problematic of "non-sensible resemblance" cross the text that we can understand as an exercise of keeping distance of the mimetic forces of the image. Letting see the theoretical horizon implied in the resemblances poetic produced, Benjamin explicit the cognition's value of the work. The modernity of this childhood's memory shows itself in this tension between poetical and theoretical dimensions.

KEYWORDS: Benjamin, mímesis, enigma

\section{Introdução}

Em um longo artigo intitulado Imitação da Natureza: contribuição à pré-história da idéia do homem criador, Blumenberg examina historicamente o processo de dissolução do conceito aristotélico de mímesis. Ora, se Aristoteles define toda produção humana com a formulação de que a arte é a imitação da natureza, isso significa que esta, compreendida em um sentido largo que abarca também a técnica, deve não apenas imitar o que é naturalmente dado, mas também completar o processo natural, imitando-o em sua produtividade espontânea. Nesta perspectiva, a natureza e a "arte" são análogas. Blumenberg mostra assim que o momento moderno na arte se caracteriza pela distinção entre criação e natureza e, portanto, pela concepção do fazer artístico como invenção e não mais como imitação : "desde que Parmigiano pintou, em 1523, seu autorretrato em um espelho convexo deformante - assim não mais mantendo e encarecendo o natural no artificial, mas com ele rompendo e transformando -, a assinatura do homem criador tornou-se, na obra de arte, sempre mais agudamente articulada à sua potência cognoscitiva". (BLUMENBERG, 2010, p. 89) A ruptura moderna com a mímesis aristotélica corresponde ao movimento pelo qual a reflexão contida no fazer artístico torna-se consciente de si mesma e de seu potencial inventivo que também é cognitivo. Isto coincide com a dissolução da referência à natureza e com a concepção da arte como um processo histórico no qual novas obras são criadas a partir das anteriores.

As vanguardas artísticas do início do século XX explicitam e pensam a reflexividade inerente à obra de arte, exacerbando assim essa tendência que articula o questionamento do caráter 
referencial da representação artística à noção de invenção ou de criação. Neste contexto, que inclui movimentos tão diferentes entre si quanto a arte abstrata e o surrealismo, podemos situar a obra de Walter Benjamin, que se singulariza pela tensão nunca resolvida entre invenção poética e especulação filosófica. A modernidade de Infância em Berlim por volta de 1900 repousa sobre essa tensão sobre a qual se constitui a estrutura do enigma artístico. Assim, o objetivo deste artigo será examinar a prosa enigmática de Infância em Berlim por volta de 1900, na qual elementos teóricos remetendo a uma reflexão sobre a imaginação, concebida como a faculdade de perceber e de produzir "semelhanças não sensíveis", são apresentados poeticamente. Estas memórias de infância não propõem uma teoria, mas constituem uma constelação de ideias estéticas na qual procedimentos artísticos - jogos de deformação de palavras, assonâncias, metáforas, figuras alegóricas - contêm elementos propriamente especulativos remetendo a este feixe de problemas que chamamos imaginação e que concerne à questão do tempo e da memória. A problemática das "semelhanças não sensíveis" atravessa o conjunto, que pode ser compreendido como um trabalho de distanciação reflexiva da imagem. Pois, deixando entrever o horizonte teórico imbricado na proliferação exuberante de semelhanças artisticamente produzidas, Benjamin deforma e desestabiliza o quadro mimético da representação, explicitando assim o valor cognitivo da obra de arte. Neste sentido, seu projeto autobiográfico, que deve muito a Proust e a Baudelaire, pode ser comparado ao autorretrato deformado do qual fala Blumenberg.

Para compreendermos como a reflexão sobre a faculdade mimética orienta e deforma a forma destas memórias de infância, que se apresentam como um conjunto discontínuo de imagens de pensamento, será preciso recorrer a certas considerações genéticas sobre os textos que não foram publicados em forma de livro durante a vida do autor. A primeira publicação em apenas um volume corresponde à edição póstuma realizada por Adorno com base nos capítulos que foram publicados na imprensa periódica alemã entre 1933 e 1935 e em dois cadernos manuscritos que o ajudaram a ordenar a série de capítulos. É esta versão que está traduzida para o português. No entanto, nos anos 1980, foram encontradas duas versões datilografadas compostas pelo próprio Benjamin. Estes documentos, que se destinavam provavelmente a editores, contém cada um apenas 30 capítulos e, embora apresentem elementos constantes, a ordem das séries e a redação diferem. O estilo da mais tardia, elaborada entre 1938 e 1939 em Paris, é bem mais sucinto do que o da mais antiga, elaborada em Berlim entre 1932 
e 1933. Ao invés de desenrolar o fio das lembranças, como o faz Proust, Benjamin torna-se mais lacônico. O que parece querer indicar não é o caráter inacabado e portanto potencialmente infinito da rememoração, mas o elemento construtivo que o permite transformar o vivido em imagens que dão muito o que pensar sem que possamos fixar os conteúdos teóricos que elas evocam sob um conceito determinado.

Diferente da edição póstuma, que se abre com os passeios da criança no parque berlinense, essa versão, dita de Paris, começa com o capítulo intitulado Loggien, sobre os cômodos do andar térreo, típicos dos imóveis berlinenses, que dão para pátios internos. Mas é o primeiro capítulo da primeira versão, A Mummerehlen, que nos parece conter uma indicação fundamental sobre o programa do livro. Pois esse personagem, que constitui uma espécie de contraponto do Corcundinha, o qual fecha as três versões conhecidas, é uma alegoria da faculdade mimética, tematizada em duas notas especulativas da mesma época. A relação entre o projeto do livro sobre as lembranças de infância e as considerações de Benjamin sobre a "semelhança não sensível" e sobre o poder de percebê-las e de produzi-las aparece também em um manuscrito do início de 1933 intitulado Sobre a lâmpada, o qual esboça passagens utilizadas na redação de A Mummerehlen. Assim, para compreender o projeto de Infância em Berlim abordaremos inicialmente a questão da semelhança.

\section{Infância, semelhança e linguagem}

Em uma carta endereçada a Scholem e escrita em Berlim no 28 de fevereiro de 1933, Benjamin dá algumas indicações sobre a composição de seu livro de memórias: “[...] há uma semana posso considerar, se eu quiser, o texto como acabado pois, com a redação do último capítulo que se tornou o primeiro na série, formando o contraponto do último, que será O Corcundinha -, o número de trinta foi atingido. Sem contar com aquele que, sob o seu conselho, descartei". (GB, IV, p. 162) O texto que Scholem Ihe havia aconselhado a descartar é O Despertar do Sexo, que se encontra todavia incluído no manuscrito datilografado de 1932-1933; apesar dessa contradição, a obra descrita coincide com as características desse documento que teria sido produzido entre 1932 e 1933.

A carta citada menciona igualmente uma reformulação da teoria da linguagem à luz da problemática das semelhanças, trabalho que estaria em relação direta com as pesquisas em torno 
do primeiro capítulo de Infância em Berlim, isto é, aquele sobre a Mummerehlen. Alguns meses mais tarde, já exilado em Ibiza e na impossibilidade de retornar a Berlim, Benjamin pede a Scholem, a quem tinha o hábito de enviar todos os seus textos, que Ihe mande uma cópia de Sobre a linguagem em geral e sobre a linguagem humana, a qual lhe permitiria retrabalhar as notas sobre a semelhança. (GB, IV, p. 214) De fato, as pesquisas sobre a faculdade mimética não apenas retomam essa teoria da linguagem de 1916, mas também estão ligadas aos questionamentos sobre a experiência da mesma época.

Um fragmento redigido entre 1931 e 1932 define a experiência como "semelhanças vividas". (Zur Erfahrung in GS, VI, p. 88) Essa pequena nota retoma ainda a crítica que Sobre o programa da filosofia vindoura, texto de 1917-1918, endereçava ao mesmo tempo a Hermann Cohen e a Kant: "Não há erro maior do que querer construir a experiência, no sentido de experiência da vida, a partir do esquema daquela que está no fundamento das ciências exatas. Não são conexões causais estabelecidas no curso do tempo, mas semelhanças vividas que são aqui decisivas." (Zur Erfahrung in GS, VI, p. 88) O tema da experiência, que remete aqui à formação filosófica do jovem Benjamin, marcada pelo neo-kantismo e pela fenomenologia², não é abandonado, mas reaparece não apenas em textos e fragmentos que podemos considerar como teóricos, mas também em trabalhos literários, e em particular na Infância em Berlim.

As pesquisas sobre a semelhança, que aparecem em várias notas e esboços dos anos trinta, incluem a redação de dois ensaios curtos e não destinados à publicação: Teoria do semelhante (Lehre vom Ähnlichen) e Sobre a faculdade mimética (Über das mimetische Vermögen). Estes dois textos reproduzem, com pequenas variações, uma passagem também usada no capítulo sobre a Mummerehlen.

A natureza engendra semelhanças; é preciso apenas pensar no mimetismo. Entretanto, o homem possui a mais alta aptidão para produzir semelhanças. O dom que ele possui de ver a semelhança é somente um vestígio da antiga e poderosa necessidade de tornar-se semelhante e de se comportar de modo semelhante. Talvez ele não possua nenhuma função superior que não seja decisivamente condicionada pela faculdade mimética. (BENJAMIN, Über das mimetische Vermögen, in GS, II-1, p. 210)

Benjamin atribui ao semelhante uma parte de objetividade: a natureza produz semelhanças. Entretanto, a aptidão humana de perceber essas semelhanças naturais seria apenas uma forma 
rudimentar da necessidade de se assemelhar a si mesmo e de se comportar mimeticamente. Essa faculdade mimética que condiciona de maneira decisiva todas as funções superiores do homem lhe permite, portanto, reunir a diversidade e a multiplicidade do vivido em uma experiência individual, a qual se inscreve necessariamente em um contexto sociocultural.

De acordo com o fragmento de 1931-1932, o conceito de experiência não deve se fundar sobre as conexões causais que caracterizam o paradigma de experiência da ciência moderna - modelo que, segundo o programa filosófico de Benjamin, teria servido de base ao criticismo kantiano - mas este se define por "semelhanças vividas". É dificil determinar o que visa Benjamin com essa expressão que aparece apenas no esboço mencionado. Entretanto, em Sobre a faculdade mimética e em Teoria do semelhante, ele forja a noção de "semelhança não sensível" para designar certas práticas miméticas que caracterizam a brincadeira infantil e que teriam sido outrora o fundamento da uma visão mágica do mundo.

Tanto para produzir como para perceber o semelhante, é preciso poder ver o mesmo no outro e o outro no mesmo, encontrar o idêntico no diferente e o diferente no idêntico. Isso vale tanto para as semelhanças percebidas na experiência sensível quanto para aquelas que não dadas ao nível da intuição, mas contruídas pelo pensamento. É a Crítica da razão pura que funda todas as funções superiores do homem sobre esse poder comparativo fundamental: o princípio de afinidade da imaginação. Este princípio, que constitui a regra indeterminada do esquematismo, contribui para a formação dos conceitos do entendimento, onde a identidade triunfa sobre a diferença, mas opera também na construção discursiva ou artística de símbolos que conservam a tensão comparativa do semelhante ${ }^{3}$.

A concepção kantiana da imaginação como uma faculdade fundamentalmente comparativa, capaz de articular o diverso do sensível e a unidade do inteligível, a diferença e a identidade, constitui sem dúvida o horizonte nunca explicitado da teoria do semelhante de Benjamin. Entretanto, adotando um ponto de vista histórico, que poderia coincidir com certas hipóteses de Cassirer sobre a passagem do mito à linguagem, ele retoma um esquema argumentativo usado por Freud ${ }^{4}$. Se não há nenhuma função superior do homem que não seja decisivamente determinada pela faculdade mimética, esta última não permanece inalterada, mas passa por transformações significativas: 
Essa faculdade tem uma história, tanto no sentido filogenético quanto no sentido ontogenético. No que diz respeito ao último, a brincadeira infantil constitui a escola dessa faculdade. Os jogos infantis são impregnados de comportamentos miméticos, que não se limitam de modo algum à imitação de pessoas. A criança não brinca apenas de ser comerciante ou professor, mas também moinho de vento e trêm. A questão importante, contudo, é saber qual a utilidade para a criança desse adestramento da atitude mimética. (BENJAMIN, A doutrina das semelhanças, in OE I, p. 108)

Segundo Benjamin, a resposta a essa questão, que está relacionada às pesquisas com vistas à redação do capítulo de abertura da Infância em Berlim, implica o exame prévio do aspecto filogenético das praticas miméticas, isto é, do papel destas no vasto campo de "semelhanças não sensíveis" próprio à magia dos primitivos e dos antigos. Essa terminologia é emprestada a Freud, que procura estabelecer semelhanças e correlações entre a vida da alma dos povos e as descobertas da psicanálise sobre a do indivíduo, sugerindo assim um paralelismo entre "desenvolvimento ontogênico" e "desenvolvimento filogênico". (FREUD, 2010 (1912-1913), p. 197) Assim o método "filogenético", adotado por Benjamin na investigação sobre a faculdade mimética, se regra reflexivamente sobre a construção de uma correlação analógica entre a experiência da criança e a dos povos primitivos. Esta analogia se mostra efetivamente produtiva no que concerne à questão do saber como a fantasia, na qual elementos individuais cruzam motivos culturais, se exprime no nível da linguagem, na produção de "semelhanças não sensíveis".

A investigação "filogenética" parece inicialmente conduzir Benjamin à hipótese de uma redução crescente do campo de ação da faculdade mimética. Pois o universo perceptivo do homem moderno parece consideravelmente mais pobre em "semelhanças não sensíveis" do que o dos povos primitivos, no qual abundavam correspondências e analogias mágicas: "nossa percepção não mais dispõe do que antes nos permitiria falar de uma semelhança entre uma constelação e um ser humano." (BENJAMIN, A doutrina das semelhanças, in OE I, p. 110) Entretanto, segundo Benjamin, as semelhanças deste tipo não teriam desaparecido, mas migrado para a linguagem. Não se trata portanto de uma perda, mas de uma transformação.

Em uma nota muito significativa, ele afirma que o processo pelo qual o centro de ação da faculdade mimética se transfere dos olhos aos lábios contém o ultrapassamento do mito. (BENJAMIN, GS, II-3, p. 958) Em um universo mítico, o homem permanece sob o jugo das 
semelhanças, cativo de sua ação que se exerce sobretudo sobre a esfera visual, na imagem. Benjamin dá como exemplo a astrologia, na qual tais correspondências mágicas determinam o destino individual a partir da configuração astral. Em contrapartida, na palavra as forças miméticas podem se liberar do mito. Tal é a conclusão de Sobre a faculdade mimética:

a linguagem seria o mais alto grau do comportamento mimético e o mais completo arquivo da semelhança não sensível: um medium no qual migraram as antigas forças de produção e de percepção mimética, até que liquidaram os poderes da magia. (BENJAMIN, Über das mimetische Vermögen, in GS, II-1, p. 213)

Esta hipótese, que coincide parcialmente com a orientação histórica da Filosofia das formas simbólicas, conduz a uma reflexão sobre a dimensão mimética da linguagem. Benjamin afirma que as "semelhanças não sensíveis" ligam o falado e o significado, o escrito e o significado, o falado e o escrito. Isto quer dizer que as palavras não são puros signos: elas contêm um teor afetivo que as liga ao que significam. Entretanto, essa carga mimética que reúne os dois termos do signo na unidade do nome não corresponde à essência do objeto visado, mas ao processo esquemático que age na linguagem. Assim, é o poder comparativo da imaginação que nos permite dizer o mesmo de outro modo no interior da língua ou entre várias línguas, na tradução. Ora, de acordo com Benjamin, esse aspecto mimético - ou esquemático - da linguagem não se funda sobre a palavra isolada pois não se separa de sua dimensão semiótica. Aquilo que nos permite produzir e perceber o semelhante no interior da linguagem é o suporte da significação, o qual implica a construção judicativa e discursiva. "O sentido tecido pelas palavras ou frases é assim o suporte sobre o qual, num relâmpago, aparece a semelhança". (BENJAMIN, Über das mimetische Vermögen, in GS, II-1, p. 213)

Teoria do semelhante e Sobre a faculdade mimética não retomam o tema que se encontra em seu ponto de partida: os comportamentos miméticos da criança que brinca. É Infância em Berlim que o desenvolve longamente. A analogia entre a filogênese e a ontogênese da faculdade mimética, que é mais propriamente sugerida do que tematizada nas duas notas, abre entretanto uma via de acesso aos elementos teóricos que se encontram no horizonte deste motivo. As reflexões sobre a faculdade mimética nos permitem concluir que a produção lúdica de "semelhanças não sensíveis" concerne fundamentalmente à relação da criança à linguagem, tanto à palavra quanto à escrita, e ao mesmo tempo também ao cosmos sócio-cultural 
e histórico que se abre a ela a partir da língua. As condutas miméticas, abundantes na brincadeira, Ihe ensinam a se apropriar da linguagem e a produzir, no suporte de sua dimensão semiótica, "semelhanças não sensíveis".

É neste sentido que o capítulo sobre a Mummerehlen retoma, com variações significativas, a passagem que aparece também nas duas notas teóricas. Os enganos da criança que balbucia suas primeiras palavras abrem aí vias profundas. É a faculdade mimética que, agindo em suas brincadeiras com a linguagem, Ihe ensina a se dissimular na língua, o que the faz assemelhar-se a objetos já simbolicamente investidos pelo meio sócio-cultural que o cerca, o da burguesia berlinense por volta de 1900. Sob o modo da fantasia, a faculdade mimética acompanha a criança em suas explorações e, sem se mostrar, deforma palavras e coisas. A deformação caracteriza sua preponderância na experiência infantil. Deformado pela onipresença da semelhança, esse mundo da infância está sempre a ponto de se fixar na imagem, assumindo contornos míticos, como ocorre no ateliê do fotógrafo, onde a criança se via cercada de ornamentos e acessórios que cobiçavam sua imagem "como as sombras do Hades cobiçam o sangue do animal sacrificado". (BENJAMIN, A Mummerehlen, in OE II, p. 99) Fixar o sujeito em sua imagem e a época em sua mitologia - não é este o perigo que atravessa Infância em Berlim? Ora, a esperança de uma redenção que não é apenas individual repousa sobre a forma do livro; sua prosa sugere o domínio linguístico no qual a faculdade mimética pode se liberar do mito: o da arte.

Em um fragmento dos anos vinte, Benjamin já concebia as formações da fantasia como deformações do que foi colocado em forma. (BENJAMIN, Phantasie, in GS, VI, p. 115) Segundo esse texto, a pura fantasia não é uma força inventiva, mas um poder deformante que se regra pela natureza e pelas ideias. Neste sentido, está no fundamento da arte embora seja "incapaz de construir uma obra de arte pois, enquanto elemento deformante [Entstaltendes], deve se referir a um elemento que recebeu uma forma [Gestaltetes]." (BENJAMIN, Phantasie, in GS, VI, p. 116) É esse elemento formal que, quando adere completamente à obra, torna-se o seu fundamento. "Mas onde ele não intervém na obra, mas é ao contrário mantido a uma distância sentimental, patética ou irônica desta, tais formações [Gebilde] fazem do mundo das formas um texto do qual tecem o comentário ou o arabesco." (BENJAMIN, Phantasie, in GS, VI, p. 116) 
Segundo Benjamin, essas configurações artísticas não são puras obras de arte pois nos levam para fora delas mesmas, ao enigma. Como as ideias estéticas, elas abrem perspectivas para o pensamento. De acordo com a argumentação de Benjamin, no melhor dos casos, no seio da expressão artística, apenas a linguagem mantém em seu poder as formações da fantasia e pode, portanto, conter suas forças de deformação. Não seria Infância em Berlim uma dessas obras enigmáticas nas quais o elemento formal é mantido ironicamente à distância? É isto o que sua prosa, que domina com maestria as forças de deformação presentes na língua, nos permite afirmar. O Corcundinha, que fecha o conjunto de textos curtos, é a própria imagem do olhar exterior que caracteriza seu estilo inigualável.

\section{Da Mummerehlen ao Corcundinha}

Em uma passagem frequentemente citada da Crônica berlinense, Benjamin atribui a qualidade de seu estilo - superior, de acordo com ele mesmo, ao de outros escritores de sua geração - à observância de uma regra simples: jamais empregar o pronome "eu", a não ser em cartas. Entretanto, é na primeira pessoa do singular que ele se exprime ao comentar esta assertiva:

Isso teve uma consequência singular que está estreitamente ligada a estas notas. Com efeito, quando um dia me foi feita a proposta de dar para uma revista - numa forma solta, subjectiva - uma série de artigos sobre tudo o que me parecia digno de atenção no dia a dia de Berlim - e quando eu aceitei - ficou claro que o sujeito, que durante tantos anos se acostumara a ficar em segundo plano não se deixava tão facilmente convidar para a cena. Mas longe de protestar, preferiu recorrer à um subterfúgio. (BENJAMIN, Berliner Chronik, GS, VI, p. 475)

A Mummerehlen e o Corcundinha, essas duas figuras tutelares colocadas, tal como duas cariátides, na abertura e na conclusão da primeira versão de Infância em Berlim, não seriam estratégias deste sujeito que procura se esconder ao mesmo tempo em que se mostra? A primeira corresponde à matéria - o fundo das representações e das imagens que se associam umas às outras - e o segundo figura a intenção de formação que se mantém à distância, no subterrâneo, nas profundezas alegóricas da prosa, e contempla do exterior as imagens da infância.

Realizada por encomenda de uma revista, a Crônica berlinense permanece inacabada e não foi publicada durante a vida do autor. Este primeiro projeto autobiográfico, abandonado possivelmente por causa do estilo excessivamente pessoal e subjetivo que acaba adquirindo, está 
na origem de Infância em Berlim, e sobretudo de sua primeira versão. O subterfúgio deste sujeito que quer permanecer oculto parece efetivamente determinar aqui o abandono do tom subjetivo e do encadeamento narrativo de lembranças pessoais em prol de uma rememoração artificialmente construída sob a forma discontínua de imagens nas quais materiais diversos - lembranças individuais ou elementos histórico-culturais - aparecem transformados, deformados e de certo modo objetivados pelo trabalho da reflexão. Não se trata aqui do infinito da rememoração proustiana, na qual o torrencial potencialmente sem fim de lembranças nasce da experiência individual da duração no tempo reencontrado da memória involuntária. O infinito ao qual remetem as imagens de Infância em Berlim é o da reflexividade que, conferindo um valor alegórico aos materiais biográficos (e pseudo-biográficos) rememorados, constrói uma rede discontínua de correspondências cujo percurso é uma tarefa infinita: a da interpretação que prolonga além da obra o olhar exterior do Corcundinha.

Guardando suas distâncias em relação à influência decisiva de Proust, o autor de Infância em Berlim se aproxima de Baudelaire: o que ele procura rememorar por meio de uma prosa retrabalhada poeticamente não é o sabor intangível do temps retrouvé, que permanece no domínio da experiência privada do indivíduo, mas a "vida anterior" ou o mundo das correspondências de que fala o poeta das Flores do Mal.

A Natureza é um templo onde vivos pilares

Deixam filtrar não raro insólitos enredos;

O homem o cruza em meio a um bosque de segredos

Que ali o espreitam com seus olhos familiares.

(BAUDELAIRE, 1985, p. 65)

Em Sobre alguns temas baudelairianos, Benjamin define o que Baudelaire entendia por correspondances como uma experiência que, procurando se estabelecer ao abrigo de toda e qualquer crise, só é possível no domínio, fundamentalmente "aurático", do culto. De acordo com ele, fora deste domínio, esta se apresenta no belo, onde "o valor cultual se manifesta como valor da arte". (BENJAMIN, Sobre alguns temas em Baudelaire, in OE III, p. 132 (GS-I-II, p. 638) Esta argumentação tem continuidade em uma nota muito significativa que, procurando pensar o belo a partir de uma referência ao ensaio sobre as Afinidades eletivas de Goethe, chega a uma formulação que remete à problemática do semelhante: 
Em sua relação com a natureza, o belo pode ser definido como aquilo que "permanece essencialmente igual a si mesmo apenas enquanto guardar o seu véu"6. [...] As correspondências nos informam sobre como devemos pensar este velamento. Usando de uma elipse certamente arriscada, poderíamos dizer que trata-se do aspecto da obra de arte que "reflete" a realidade [Abbildende]. As correspondances apresentam a instância diante da qual o objeto da arte é descoberto como algo que reflete fielmente, e é nisso mesmo completamente aporético. Se quiséssemos traduzir esta aporia no próprio material da linguagem, seria preciso finalmente definir o belo como o objeto da experiência no estado de semelhança. (GS, I-II, p. 639 (minha tradução). O.E. III, p. 133.

No belo, a tensão comparativa própria à experiência do semelhante permanece visível. Dito de outro modo, em termos kantianos, no livre jogo da imaginação e do entendimento as afinidades sobre as quais se regra o esquematismo permanecem eletivas: o conflito da identidade e da diferença não se resolve com o triunfo da identidade, como no conceito. Neste sentido, as correspondências baudelairianas remetem à dimensão mimética da arte, compreendida a partir de Valery como "cópia servil do que é indefinível nas coisas" (GS, I-II, p. 639. O.E. III, p. 133), isto é, para retomar a expressão utilizada por Benjamin, como um tipo de imitação "não sensível" que se endereça às relações que entretemos com as coisas. Nesta perspectiva, a mímesis artística não concerne à imitação objetiva dos dados naturais, mas à analogia entre a criação artística e o processo natural de geração de formas.

É neste sentido que, no final do capítulo sobre a Mummerehlen, a obra de arte aparece como uma imitação da experiência infantil das "semelhanças não sensíveis". Neste texto, Benjamin conta a anadota do pintor chinês que, enquanto mostrava seu quadro aos amigos, nele entra e desaparece na paisagem pintada. Essa história, que nos "leva novamente à obra da Mummerehlen", sugere que a arte pode ser vista como um retorno àquela "vida anterior" da qual falam as correspondências de Baudelaire. Efetivamente, este personagem imaginário conduz a criança em um mundo inteiramente dominado pela semelhança.

Ora, em Infância em Berlim, a segunda natureza das correspondências é a cidade tal como a vê o flâneur, aquele que aprendeu a se perder nas ruas como nas veredas de uma floresta. É no movimento reflexivo da rememoração que a criança antecipa essa experiência mais tardia da flânerie. Sob esse olhar infantil deformado pelas potências miméticas, a cidade torna-se uma floresta de símbolos que se apodera do interior burguês e se projeta no longínquo. No 
Panorama Imperial ou naqueles cartões postais que contêm a atmosfera do Blumeshof onde mora a avó apreciadora de viagens, o distante pertence a este universo familiar. São as forças miméticas que estendem assim esse cosmos urbano no qual as feirantes da Magdeburger Platz tornam-se deusas da fertilidade e a professora possui as nobres qualidades cujas iniciais compõem o seu nome. O "eu" que se contava na Crônica berlinense desaparece nesta Berlim deformada pelo encantamento da semelhança: ele se esconde na imagem.

É a uma tal concepção "aurática" da obra de arte como atualização da projeção do sujeito no mundo transfigurado pela semelhança, reminiscência de uma percepção onírica ou primitiva, que remetem as correspondências baudelairianas. Entretanto, a poesia de Baudelaire é precisamente testemunha de uma crise da representação artística que, segundo Benjamin, seria parte integrante de uma crise da percepção. Segundo sua leitura, ao invés de procurar ultrapassá-la com um simples retorno nostálgico, o poeta das Flores do Mal acentua a fissura na unidade simbólica da obra de arte: sua poesia é fundamentalmente alegórica. Baudelaire não é somente o poeta destas correspondências que se subtraem à finitude, pois são dados da rememoração, mas é também o poeta do spleen, da passagem inexorável do tempo e da separação radical entre o sujeito e o objeto na experiência banalizada do mundo moderno.

Se as correspondencias baudelairianas falam de uma experiência em estado de semelhança que se traduz em um presente pleno, o spleen corresponde à consciência de um tempo homogêneo e vazio, o tempo que passa. Uma tal correlação aparece igualmente, embora de outro modo, na Infância em Berlim. Pois, neste livro, o motivo onipresente da semelhança surge da consciência da discontinuidade temporal que corresponde à própria condição do rememorar. Ora, o esquecimento que estabelece a distância reflexiva entre o "eu" que se rememora e as imagens nas quais o mundo rememorado aparece deformado pela semelhança é coisa do Corcundinha.

Como a Mummerehlen, este homenzinho encontrado em uma canção infantil de Georg Scherer é uma figura alegórica que remete ao projeto do livro, à intensão que se concretiza em sua forma. Se a primeira acompanha a criança em um mundo em eterna deformação que, como as habitações das duas avozinhas ${ }^{7}$, parece escapar à morte, o segundo é o gênio da finitude e do esquecimento, seu olhar agudo marca a discontinuidade que permite deformar na série de imagens os materiais histórico-culturais e biográficos. Ele observa do exterior as 
lembranças da infância e, Ihes tomando a parte do esquecimento, nelas acrescenta o infinito da reflexividade. Corcunda, ele é deformado; isto é, corresponde ao elemento colocado em forma sobre o qual se exercem as forças miméticas em um processo de deformação. Assim, é sobre o suporte semiótico tecido pelo Corcundinha que aparece em todo o seu brilho o mundo transfigurado pela semelhança; a rememoração do eterno presente das correspondências resulta efetivamente da formação reflexiva do texto e das estratégias linguísticas que este coloca em cena. As implicações estéticas da Infância em Berlim repousam sobre o movimento de formação que estiliza a rememoração em um conjunto de imagens de pensamento: a redenção também é coisa do Corcundinha.

\section{Notas}

1 Para uma análise detalhada das diferentes versões e outros manuscritos que nos permitem retraçar uma genealogia do projeto de Infância em Berlim por volta de 1900, cf. Lindner, Burkhardt. Schreibprozeß, Finisierung und verborgene Erinerungstheorie in Benjamins 'Berliner Kindheit'. Zur erstmaligen Edition des Gesamtnachlasses, in: Brandes, P. e Lindner, B., Finis. Paradoxien des Endes. Würzburg: Königshausen \& Neumann, 2010. Cf. também Giuriato, Davide. Mikrographien. Zu einer Poetologie des Schreibens in Walter Benjamins Kindheitserinnerungen (1932-1939). Munich: Wilhelm Fink, 2006.

2 Sobre a fontes neo-kantianas e fenomenológicas do pensamento de Walter Benjamin, cf. Fenves, P., The Messianic Reduction. Walter Benjamin and the shape of time. Stanford: Stanford University Press, 2010. Cf. também Steiner, U., Benjamin and Kant: the Experience of Modernity, in: Lottes, G. e Steiner, U. (ed.), Immanuel Kant: German Professor and World-Philosopher. Saarbrücken/ Wehrhahn, 2007

3 Em uma releitura do esquematismo de Kant e da Poética de Aristoteles, Ricœur tematizou esse "trabalho da semelhança" que, segundo ele, constituiu o coração da proposição metafórica. Cf. Ricœur, P. Le travail de la ressemblance, in: La Métaphore vive. Paris: Seuil, 1997 (1975).

4 A referência às pesquisas de Freud sobre o totemismo e sobre a magia, que não é explicitada nos dois textos acabados, se encontra em outras anotações sobre o problema da semelhança. Cf. GS, II-3, p. 957 e p. 958.

5 Benjamin cita o poema em francês: "La Nature est un temple où des vivants piliers/Laissent parfois sortir de confuses paroles ;/L'homme y passe à travers des forêts de symboles/ Qui l'observent avec des regards familiers".

6 Benjamin cita aqui seu próprio ensaio sobre As Afinidades eletivas de Goethe.

7 Tante Lehmann e a avó materna. Cf. Rua Steglitz esquina com Genthin e Rua Blumeshof, 12, Infância em Berlim por volta de 1900, in: OE II, p. 85-87 e p. 95-98. 


\section{Referências}

\section{Fontes}

BENJAMIN, W. Gesammelte Schriften. (Editado por R. Tiedemann e H. Schweppenhäuser sob a supervisão de T. W. Adorno et G. Scholem). Frankfurt/Main: Suhrkamp, 1991.

BENJAMIN, W. Gesammelte Briefe. Frankfurt/Main: Suhrkamp, 1995.

BENJAMIN, W. Berliner Kindheit um Neuzehnhundert, die Gießener Fassung. Frankfurt/Main: Suhrkamp, 2000.

BENJAMIN, W. Enfance berlinoise vers 1900. La version de 1932-1933 (dita "de Giessen"). (Tradução francesa de Pierre Rusch, prefácio e notas de Patricia Lavelle). Paris: Editions de l'Herne, 2012.

BENJAMIN, W. Obras Escolhidas, I, // e III, (Traduções de Sergio Paulo Rouanet, Rubens Rodrigues Torres Filho e José Carlos Martins Barbosa, prefácio de Jeanne Marie Gagnebin). São Paulo: Brasiliense, 1995.

BAUDELAIRE, C. CEuvres. Paris: Gallimard (Bibliothèque de la Pléiade), 1995.

BLUMENBERG, H. Imitação da natureza: contribuição à pré-história do homem criador. (Tradução de Luiz Costa Lima). In: Costa Lima, L. (org.). Mímesis e a reflexão contemporânea. Rio de Janeiro: EDUERJ, 2010.

FREUD, S. Totem et tabou (Tradução de Janine Altounian, André Bourguignon, Pierre Cotet, Alain Rauzy com a colaboração de Florence Baillet, prefácio de Jean-Michel Hirt). Paris: P.U.F, 2010.

FREUD, S. Crítica da faculdade do juízo (Tradução de Valério Rohden e António Marques). Rio de Janeiro: Forense Universitária, 1995. FREUD, S. Crítica da razão pura (Tradução de Manuela Pinto dos Santos e Alexandre Fradique Morujão, introdução e notas de Alexandre Fradique Morujão). Lisboa: Fundação Calouste Gulbenkian, 1997.

FREUD, S. CEuvres philosophiques (éd. F. Alquié avec la collaboration de A. J-L. Delamare, J. Ferrari, L. Ferry, F. de Gandt, P. Jalabert, J.-R. Ladmiral, M. B. de Launay, B. Lortholary, J. Masson, O. Masson, F. Marty, A. Philonenko, A. Renaut, J. Rivelaygue, J.-M. Vaysse, H. Wismann, S. Zac). Paris: Gallimard (Bibliothèque de la Pléiade), 1980-1986.

\section{Comentários}

FENVES, P. The Messianic Reduction. Walter Benjamin and the shape of time. Stanford: Stanford University Press, 2010.

GIURIATO, Davide. Mikrographien. Zu einer Poetologie des Schreibens in Walter Benjamins Kindheitserinnerungen (1932-1939). Munich: Wilhelm Fink, 2006.

LINDNER, Burkhardt. Schreibprozeß, Finisierung und verborgene Erinerungstheorie in Benjamins 'Berliner Kindheit'. Zur erstmaligen 
Edition des Gesamtnachlasses. In: Brandes, P. e Lindner, B., Finis. Paradoxien des Endes. Würzburg: Königshausen \& Neumann, 2010. STEINER, U. Benjamin and Kant: the Experience of Modernity. In: LOTTES, G. e STEINER, U. (ed.). Immanuel Kant: German professor and world-philosopher. Saarbrücken/Wehrhahn, 2007.

\section{Abreviações usadas}

GS = Gesammelte Schriften, editado por R. Tiedemann et H. Schweppenhäuser sob a supervisão de T. W. Adorno et G. Scholem. Frankfurt/Main: Suhrkamp, 1991.

$\mathrm{GB}=$ Gesammelte Briefe. Frankfurt/Main: Suhrkamp, 1995.

$\mathrm{OE}=$ Obras Escolhidas, I, II e III, traduções de Sergio Paulo Rouanet, Rubens Rodrigues Torres Filho, José Carlos Martins Barbosa, prefácio de Jeanne Marie Gagnebin. São Paulo: Brasiliense, 1995. 